Check for updates

Cite this: RSC Chem. Biol., 2022, 3,18

Received 26th July 2021,

Accepted 5th November 2021

DOI: $10.1039 / \mathrm{d} 1 \mathrm{cb} 00154 \mathrm{j}$

rsc.li/rsc-chembio

\title{
Cyclic peptide drugs approved in the last two decades (2001-2021)
}

\begin{abstract}
Huiya Zhang and Shiyu Chen (D) *
In contrast to the major families of small molecules and antibodies, cyclic peptides, as a family of synthesizable macromolecules, have distinct biochemical and therapeutic properties for pharmaceutical applications. Cyclic peptide-based drugs have increasingly been developed in the past two decades, confirming the common perception that cyclic peptides have high binding affinities and low metabolic toxicity as antibodies, good stability and ease of manufacture as small molecules. Natural peptides were the major source of cyclic peptide drugs in the last century, and cyclic peptides derived from novel screening and cyclization strategies are the new source. In this review, we will discuss and summarize 18 cyclic peptides approved for clinical use in the past two decades to provide a better understanding of cyclic peptide development and to inspire new perspectives. The purpose of the present review is to promote efforts to resolve the challenges in the development of cyclic peptide drugs that are more effective.
\end{abstract}

\section{Introduction}

Since insulin was first used in the clinic almost 100 years ago, ${ }^{1}$ the spectrum of potency, specificity and safety of the peptide chain enhanced by cyclization has demonstrated the fundamental characteristics of cyclic peptides. Among the $>60$ FDAand EMA-approved peptides, ${ }^{2}$ two-thirds are in the cyclic form and have an important role in the modern pharmaceutical industry. ${ }^{3}$ The constraint introduced by cyclization makes the peptide chain more conformationally stable, which improves the target protein binding affinity and reduces nonspecific binding due to fewer alternative conformations. ${ }^{4}$ Reduced conformational flexibility decreases the chance of the molecules fitting into the protease catalytic site and the proteomic resistance is improved..$^{5}$ Cyclization also increases the efficacy of peptide chains by forming a larger interacting surface for intervening protein-protein interactions. ${ }^{6}$ Overall, peptide chain cyclization causes the cyclic peptides to be intrinsically different from linear peptides. ${ }^{7,8}$

Cyclization improves not only the structural properties of peptide chains but also the pharmacokinetic properties for absorption and biological membrane permeability that is necessary for reaching protein targets. ${ }^{9}$ The constrained structure of peptides can cause them to have a lower energy barrier for adapting to the membrane environment and binding to transporting proteins, which increases both passive diffusion and active transport. ${ }^{10}$ Cyclic peptides can also be further

Biotech Drug Research Center, Shanghai Institute of Materia Medica, Chinese Academy of Sciences, Shanghai 201203, China.E-mail: chenshiyu@simm.ac.cn improved by introducing noncanonical elements to improve both their pharmacokinetic and pharmacodynamic properties. ${ }^{11}$ The introduction of lipophilic side chains greatly improves their affinity to plasma carrier proteins, helps them to avoid renal clearance and improves their pharmacokinetic properties. ${ }^{12,13}$ Alternative strategies, including conjugation with albumin and immunoglobulin to extend the half-life, are also commonly adopted, and the frequency of administration can be reduced. ${ }^{14,15}$

However, cyclization makes the development of cyclic peptide drugs more challenging compared to the development of linear peptides. ${ }^{4,16}$ The majority of approved cyclic peptides are engineered from natural analogs by keeping the overall cyclic peptide structure to maintain affinity to the target protein..$^{17,18}$ Canonical peptide chains are conventionally cyclized by headtail amidation, disulfide bond formation between cysteines, and sidechain amine to C-terminal carboxyl group and sidechain carboxyl group to N-terminal amidations. ${ }^{19-21}$ More recently, peptide cyclization was advanced by the introduction of noncanonical elements that can induce cyclization of orthogonal reactive groups. ${ }^{22,23}$ The introduction of noncanonical elements in cyclic peptides expanded not only the chemical space of cyclic peptides but also the library diversity, which is very important for screening potent ligands. ${ }^{23}$ The combination of these developments in diverse chemical and biological technologies contributed to the rapid development of cyclic peptide drug discovery. ${ }^{4}$

In this review, we summarize the discovery and development of cyclic peptides that have been approved in the last two decades. Chemical structures, mechanisms of action and metabolic properties are analyzed to unveil the important factors for cyclic peptide drug development and utilization in clinical 
situations. We mainly focus on cyclic peptide therapeutics by excluding peptides with $>20$ amino acids that show properties similar to small proteins and peptidomimetics with $<5$ residues that show physical properties similar to small molecules. Taking advantage of many recently developed technologies for building cyclic peptide libraries with a diversity of billions by translating genetic variations, cyclic peptides with a length in this range can be routinely screened and rapidly synthesized for hit discovery and affinity maturation to obtain cyclic peptides suitable for drug development. The opportunities and perspectives for cyclic peptide drug development are also discussed.

\section{Targeting intracellular proteins}

Developing cell permeable cyclic peptides that can reach intracellular targets is a challenging task. ${ }^{10}$ Unlike small molecules that enter cells primarily through passive diffusion, peptidebased molecules greater than 1000 Da have distinct physical properties, mechanisms, and cell permeability ability, and currently available theories for improving the ADMET (absorption, distribution, metabolism, excretion, and toxicity) properties of small molecules do not apply to the development of cyclic peptides. ${ }^{24}$ Available theories for designing cell permeable peptides, such as passive diffusion, endocytosis and carrier-mediated transport with (CPPs), ${ }^{25,26}$ are limited in many aspects. It is well known that CPPs bind to several extracellular receptors and can be actively imported. ${ }^{27,28}$ It is necessary to incorporate specific elements in the sequence of the peptide chain, and these chemical alterations can impact the conformation of peptide drugs and further reduce the target binding affinity. Improving the hydrophilic and lipophilic characteristics of peptides with modification strategies such as $N$-methylation, side chain lipidation, ${ }^{29,30}$ and introduction of D-amino acid substituents ${ }^{31}$ can all increase the general ability of peptides to pass through lipid bilayer-based cell membranes. However, the fundamental difficulty associated with developing cell-permeable peptides is the lack of knowledge on the mechanisms associated with cell penetration. ${ }^{10}$ Five properties, including hydrogen-bonding potential, conformation, charge, size, and hydrophobicity, were observed to influence cell permeability. ${ }^{24}$ The extra stability of cyclization introduced into cyclic peptides makes them ideal candidates for entering cells through endocytosis, which requires a resistance to the variety of enzymes present in lysosomes. ${ }^{32}$

Romidepsin (1, Table 1 and Fig. 1a) and voclosporin (2, Table 1 and Fig. 1a) are the only two cyclic peptides approved in the past two decades that target intracellular protein targets. ${ }^{33,34}$ Romidepsin is a natural bicyclic peptide obtained from the bacterium Chromobacterium violaceum in 1994 and approved by the FDA in 2009 for cutaneous T-cell lymphoma (CTCL). ${ }^{35,36}$ Romidepsin is a rather small depsipeptide that contains a head-tail lactone cyclization and a pair of disulfide bridges. ${ }^{37}$ Although romidepsin can be chemically synthesized, the primary source of romidepsin was manufactured by fermentation. Romidepsin is a prodrug in which the disulfide is reduced to two thiols in the intracellular matrix. ${ }^{38}$ Once

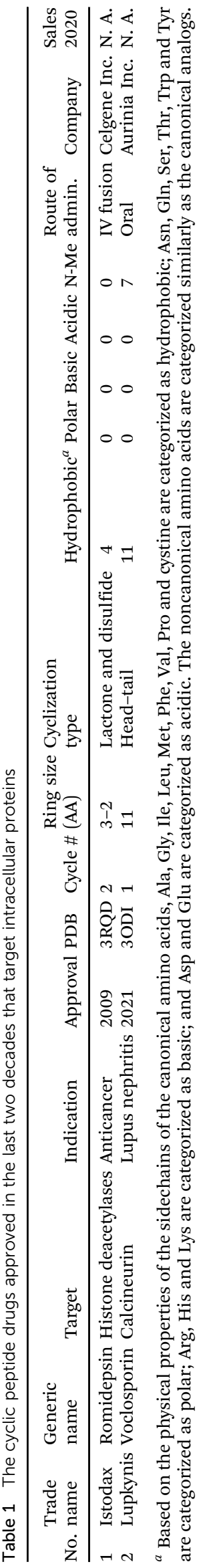



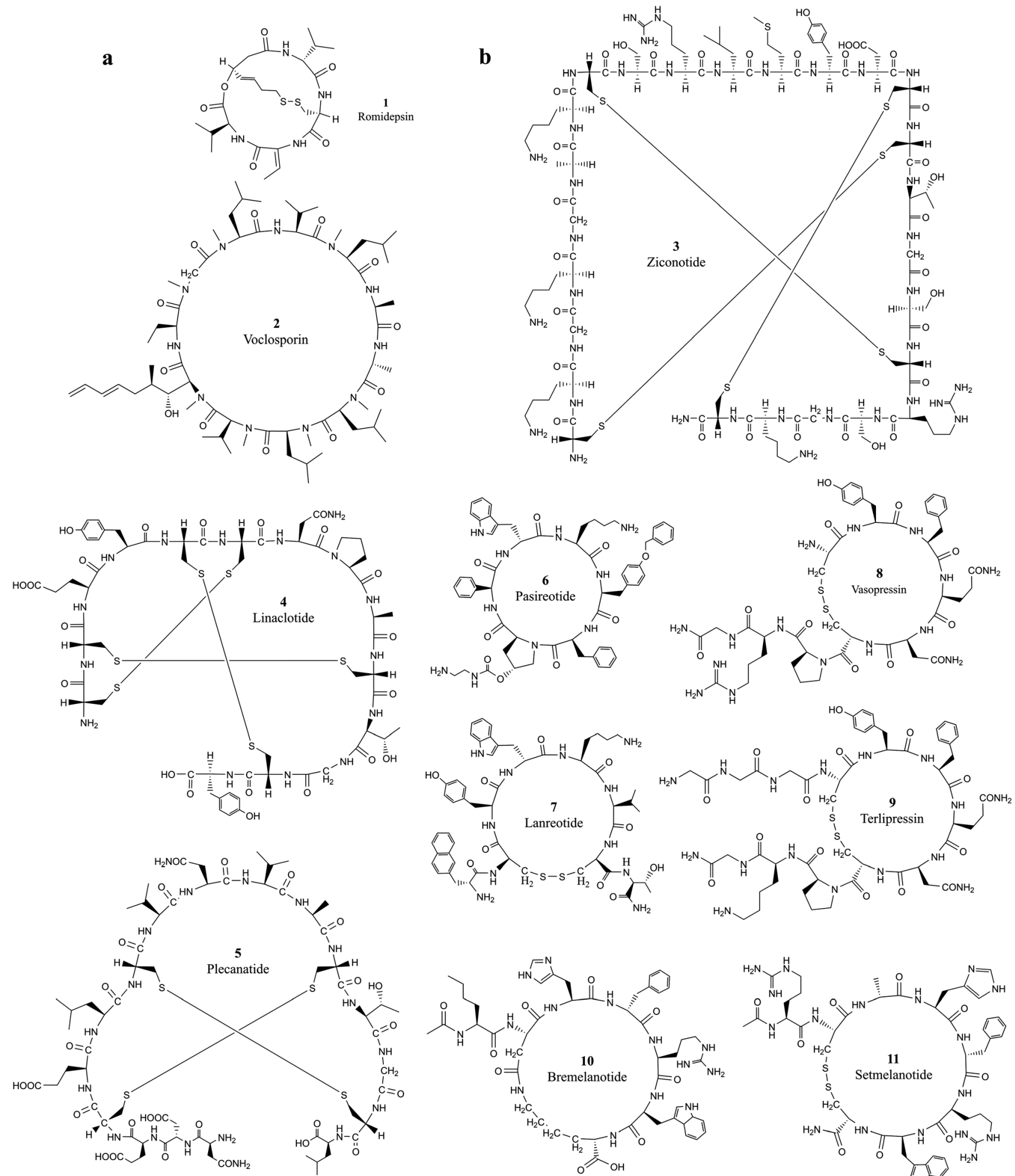

Fig. 1 The chemical structures of cyclic peptides from Tables 1 and 2 that target (a) intracellular proteins and (b) extracellular proteins.

reduced, thiols can chelate zinc in the zinc-dependent active site of histone deacetylase (HDAC) enzymes, thereby inhibiting histone deacetylases and inducing cell apoptosis. ${ }^{39}$ The half-life of intravenously administered romidepsin is approximately 3.5 hours. $^{40}$ In rats, the primary route of elimination of romidepsin and its metabolites is the bile with subsequent excretion in feces, and approximately $20 \%$ hepatic clearance is metabolized. ${ }^{41}$ Because it does not rely on enzymatic degradation or hepatic or renal excretion, the drug is safe to use in patients with any degree of hepatic or renal impairment. ${ }^{42}$ 
Recently, Istodax was withdrawn as a treatment for peripheral Tcell lymphoma, while it remains on the market for treatment of patients with cutaneous T-cell lymphoma (CTCL) who have received at least one prior systemic therapy. ${ }^{43}$

Voclosporin was recently approved by the FDA for the treatment of lupus nephritis (LN) on January 22, 2021. ${ }^{44}$ Voclosporin was developed from ciclosporin with enhanced potency and metabolic stability. ${ }^{45}$ The rationale of the optimization is to replace the butenyl group of the first residue 4- $[(E)$ 2-butenyl]-4, $N$-dimethyl-l-threonine (Bmt1) in cyclosporin $\mathrm{A}$ (CsA) with 4-[(2E,4EZ)-2,4-pentadienyl]-4,N-dimethyl-l-threonine (E-MePmt1) to optimize its fit against the hydrophobic $\mathrm{Cn}$ surface to increase the binding affinity. ${ }^{46,47}$ Voclosporin is 11 residues long containing a single D-amino acid with head-tail cyclization. Some of the amino acid substrates become $\mathrm{N}$ methylated by $S$-adenosyl methionine. ${ }^{48}$ Voclosporin plays an important role in inhibiting T-cell proliferation and preventing the release of proinflammatory cytokines by blocking the activity of the calcium-regulated serine-threonine phosphatase calcineurin. ${ }^{49}$

\section{Targeting outer membrane proteins}

Half of the cyclic peptides approved in the last twenty years target extracellular protein targets, which primarily interact with G protein-coupled receptors (GPCRs). So far most GPCRtargeting therapeutics are small molecules; ${ }^{50}$ in contrast, the endogenous ligands for many GPCRs are peptides (comprising 50 or fewer amino acids), ${ }^{51}$ which suggests that this class of molecules could be therapeutically useful for being modified to develop peptide-based therapeutics. However, the short halflife of most naturally occurring linear and temporary peptide ligands severely hinders their development as drugs. The goal of developing peptide-based therapeutics from endogenous ligands is to preserve and exploit the native properties of high affinity, selectivity and potency while at the same time improving the unfavorable pharmacokinetic properties including the short half-life, rapid degradation, high levels of clearance, and even the oral bioavailability by overcoming gastrolienal degradation and poor membrane permeability. ${ }^{52,53}$ Although peptide therapy with a short half-life is desirable in some cases, extending the half-life of peptide therapies is one of the primary goals of drug development. ${ }^{54}$ Cyclization, a common strategy applied to rigidify the conformation of the peptide chain, can benefit the development of peptide-based therapeutics by increasing the plasma half-life and reducing enzymatic metabolism and renal elimination. In the past two decades, nine cyclic peptides that target membrane proteins were approved for clinic use (Table 2 and Fig. 1b). The ring size and amino acid composition were also summarized for comparison with the cyclic peptide therapeutics targeting intracellular proteins, and a trend in the population of more hydrophobic amino acids in the cell-penetrating peptides can be observed.

Ziconotide (3, Table 2 and Fig. 1b) is a synthetic version of $\omega$-conotoxin MVIIA ( $\omega$-MVIIA) isolated from the venom of the snail Conus magus. $\omega$-MVIIA contains 25 residues, and 6 of the

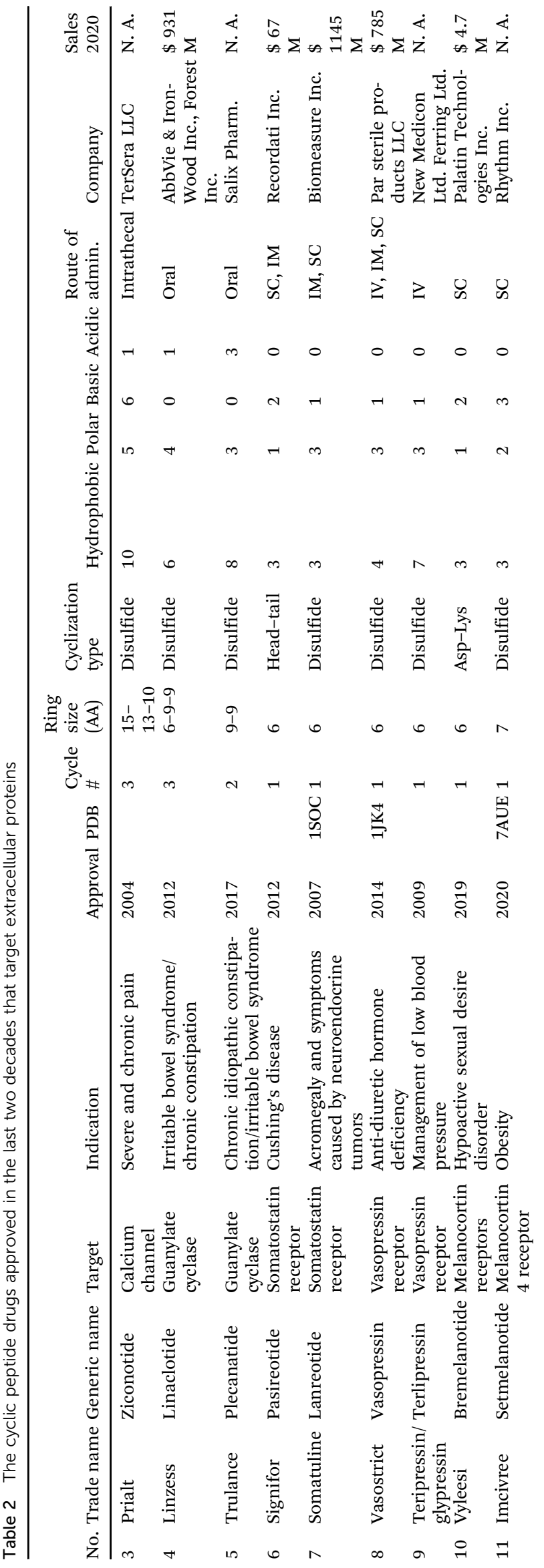


amino acids are cysteines that are linked in three pairs of disulfide bonds. ${ }^{55}$ The NMR structure revealed that $\omega$-MVIIA has a stable antiparallel $\beta$-sheet structure in solution. ${ }^{56,57}$ As a potent and selective blocker of N-type calcium channels, ziconotide was approved for the treatment of severe chronic pain in $2004 .{ }^{58}$ Evidence suggests that ziconotide delivers its antinociceptive efficacy by reducing the release of pronociceptive neurotransmitters in the dorsal horn of the spinal cord, thereby inhibiting pain signal transmission. ${ }^{59}$ Ziconotide has only limited ability to cross the blood-brain barrier. To achieve optimal analgesic efficacy with reduced potential for serious side-effects, ziconotide must be administered intrathecally. ${ }^{59,60}$

Linaclotide (4, Table 2 and Fig. 1b), an orally administered 14-amino acid synthetic peptide, is a first-in-class, high-affinity guanylate cyclase C agonist (GCCA) developed in the 1990s. ${ }^{61}$ Linaclotide is homologous to the paracrine peptide hormones guanylin and uroguanylin ${ }^{62}$ and was modified to confer a higher binding affinity as a guanylate cyclase C (GC-C) agonist along the longitudinal axis of the gastrointestinal tract regardless of changes in $\mathrm{pH}$ between 5 and $8 .^{63,64}$ The active conformation of linaclotide is stabilized by three intramolecular disulfide bridges and developed for the treatment of irritable bowel syndrome with constipation (IBS-C). ${ }^{65}$ Linaclotide is minimally absorbed by the intestine and occurs through the local activation of intestinal GC-C receptors on the intestinal epithelium. Linaclotide was degraded rapidly in mouse small intestinal fluid during in vitro assays with a calculated first-order half-life of 3 minutes. ${ }^{66}$

Plecanatide (5, Table 2 and Fig. $1 \mathrm{~b}$ ) is a 16-amino-acid peptide nearly structurally identical to human uroguanylin apart from the substitution of Asp3 with Glu3. ${ }^{63}$ Plecanatide is constrained by two pairs of disulfide bridges and adopts active conformations for binding guanylate cyclase-C (GC-C) receptors at $\mathrm{pH} 5.0$, the $\mathrm{pH}$ value of the duodenum and proximal jejunum. ${ }^{67}$ Activation of GC-C receptors in the GI tract stimulates intracellular production of cyclic guanosine monophosphate (cGMP), which then activates cystic fibrosis transmembrane conductance regulators (CFTRs) and cGMPdependent protein kinase G-II. ${ }^{68}$ The activation of both CFTRs and cGMP-dependent protein kinase G-II produces an efflux of chloride ions from enterocytes lining the GI tract, resulting in an efflux of water into the intestinal lumen. ${ }^{63,64,69,70}$ As with most orally ingested peptides, plecanatide is degraded by intestinal enzymes, and a very little amount of the active drug enters systemic circulation. ${ }^{71}$

Pasireotide (6, Table 2 and Fig. 1b) is the second-generation analog of somatostatin, a naturally occurring inhibitory hormone that interacts with $\mathrm{G}$ protein-coupled somatostatin receptors and blocks the release of several other hormones, including growth hormone, thyroid-stimulating hormone (TSH), insulin and glucagon. ${ }^{72}$ Pasireotide has a 40 -fold increased affinity to somatostatin receptor 5 compared to other somatostatin analogs. ${ }^{73}$ Pasireotide is a hexapeptide with headto-tail cyclization. Pasireotide binds with a higher affinity to somatostatin receptor 1 (SSTR1, 30-fold), SSTR3 (5-fold), and SSTR5 (39-fold) and with the same affinity to SSTR2 when compared with octreotide, a higher affinity to SSTR1 (19-fold), SSTR3 (9-fold), and SSTR5 (106-fold), and the same affinity to SST2R (2-fold) when compared with lanreotide. ${ }^{18,19}$ Pasireotide was approved for the treatment of Cushing's disease by the $\mathrm{EMA}^{74}$ and FDA in 2012. ${ }^{75}$ Pasireotide LAR was approved by the FDA for the treatment of acromegaly in December $2014 .^{76}$

Lanreotide (7, Table 2 and Fig. 1b) is also an octapeptide analog of somatostatin, and it was cyclized by a pair of disulfides formed between cysteine 2 and cysteine 7. Several strategies were developed for extending the half-life of lanreotide. ${ }^{77}$ Slow-release formulation, lanreotide sustained release (lanreotide SR), has an extended half-life of 4.5 days. $^{78}$ Lanreotide embedded in the microspheres of biodegradable polymers can be administered at a dose of 30 or $60 \mathrm{mg}$ every 7-14 days. ${ }^{79}$ Lanreotide was approved for acromegaly treatment in Europe in the 1990s. The FDA approved lanreotide for the treatment of acromegaly in 2007, metastatic gastroenteropancreatic neuroendocrine tumors (GEP-NETs) in 2014 and for the treatment of carcinoid syndrome in $2017 .^{80}$

Vasopressin (8, Table 2 and Fig. 1b) is an antidiuretic hormone developed from a natural nonapeptide with nine amino acids cyclized by a disulfide bond between Cys4 and Cys9. Vasopressin was discovered in $1928,{ }^{81}$ and its sequence was elucidated in $1951 .^{82-84}$ In humans, vasopressin is encoded by the mRNA for preproneurophysin II. Vasopressin is nonselective with affinity for activating vasopressin V1a, V2, and $\mathrm{V} 1 \mathrm{~b}$, and oxytocin receptors. Vasopressin mediates vasoconstriction by activating the V1 receptor, consequently promoting antidiuresis activity and exerting procoagulant activity on vascular smooth muscle. ${ }^{85}$ Vasopressin was branded as Pitressin and marketed for clinical use almost 100 years ago. Par Sterile Products received new drug applications (NDAs) from the FDA for branding Vasostrict in hypotensive adult patients with vasodilatory shock. ${ }^{86}$ Vasopressin shows great advantages over other medications in the treatment of septic shock by increasing blood pressure. ${ }^{87}$

Terlipressin (9, Table 2 and Fig. 1b) is a synthetic long-acting vasopressin analog with a half-life of 6 hours in contrast to 10 min for vasopressin. ${ }^{88}$ Terlipressin acts on vasopressin receptors $\mathrm{V} 1 \mathrm{a}, \mathrm{V} 1 \mathrm{~b}$ and $\mathrm{V} 2$, and has an improved safety profile and fewer side effects than vasopressin. ${ }^{89,90}$ Terlipressin is metabolized by endopeptidases to form lysine vasopressin by removing the triglycine residues at the $\mathrm{N}$-terminal end of the cyclic peptide. Terlipressin has similar effects, but this drug has been used in far fewer patients. ${ }^{87}$

Bremelanotide (10, Table 2 and Fig. 1b) is a heptapeptide cyclized between the sidechains of Asp2 and Lys7 to form the lactam analog of $\alpha$-melanocyte-stimulating hormone ( $\alpha$-MSH) ${ }^{91}$ Bremelanotide was originally developed as a potential sunless tanning agent and accidentally discovered to cause sexual arousal. Bremelanotide is a non-selective agonist of melanocortin receptors, primarily of the MC3 and MC4 receptors. ${ }^{92}$ Activation of G-protein coupled MC receptors will cause increased intracellular production of cAMP, calcium mobilization and receptor internalization, and subsequently activates dopamine terminals in the medial preoptic area (MPOA). ${ }^{93,94}$ Dopamine (DA) released in the 
MPOA mediates a variety of physiological effects, including the activation of sexual arousal. Bremelanotide has a half-life of 2.7 hours and is administered by subcutaneous injection before anticipated sexual activity for the treatment of generalized hypoactive sexual desire disorder (HSDD) in premenopausal women. $^{95}$

Setmelanotide (11, Table 2 and Fig. 1b) is a disulfide cyclized octapeptide that preferentially agonizes melanocortin 4 receptor $(\mathrm{MC} 4 \mathrm{R})$ with an $\mathrm{EC}_{50}$ of $0.27 \mathrm{nM}^{96}$ Terlipressin and setmelanotide are the only two approved cyclic peptides that were developed from the natural linear hormone by introducing a cyclization bridge to lock the cyclic conformation of the partial sequence bound to the target. Setmelanotide is a nonselective melanocortin receptor initially developed from $\alpha$-MSH by Ipsen. ${ }^{96}$ Setmelanotide improves energy homeostasis by producing satiety signaling and regulating behavioral and metabolic processes. ${ }^{97-99}$ Setmelanotide can effectively decrease weight in obese individuals with MC4R deficiency. ${ }^{100,101}$ Setmelanotide can also reduce hunger and body weight in individuals with obesity due to pro-opiomelanocortin (POMC) deficiency or leptin receptor deficiency. ${ }^{102,103}$

\section{Antimicrobial cyclic peptides}

The high potency and low toxicity of cyclic peptides make them ideal for developing antimicrobials for targeting microbial proteins that have no or low similarity to human proteins. ${ }^{104}$ In the past two decades, four antibacterial and three antifungal cyclic peptides were approved for clinical use (Table 3 and Fig. 2). All of these cyclic peptides were developed from natural metabolic products that were evolved and produced by organisms for eliminating competitors. ${ }^{105}$ The application of cyclic peptides in developing antimicrobials demonstrates the strength of their stable structure in binding to relatively small targets, which can only be achieved by large proteins in traditional beliefs. ${ }^{106}$ The action of cyclic peptides depends on a combination of secondary structure, charge, and hydrophobicity and amphipathicity properties, distinct from small molecules' binding mode. ${ }^{107}$ In this section, the structures and action mechanisms of selected antimicrobials will be described and discussed for unveiling the importance of cyclic peptides.

Daptomycin (12, Table 3 and Fig. 2) is a cyclic lipopeptide antibiotic isolated from Streptomyces roseosporus. ${ }^{108,109}$ Daptomycin is 13 residues in length with two noncanonical amino acids, 10 of which are arranged in a cyclic format by forming a lactone structure between the sidechain of Thr4 and the C-terminus. Daptomycin acts by inserting its decanoic acid into the cell wall of Gram-positive bacteria in a phosphatidylglyceroldependent fashion. ${ }^{110}$ Aggregated daptomycin creates holes in the membrane of targeted bacteria and disrupts the curvature of the membrane, resulting in ion leakage and a loss of membrane potential. Consequently, the cell activities of protein, DNA, and RNA synthesis are inhibited and apoptotic cell death is induced. ${ }^{111}$ The half-life of daptomycin in adult patients is around 8 hours and the majority (78\%) remains unchanged and eliminated by excretion into the urine. ${ }^{112}$

Telavancin (13, Table 3 and Fig. 2) is a semisynthetic derivative of vancomycin obtained by alkylating the vancosamine nitrogen with a decylaminoethyl side chain and a hydrophilic phosphonomethylaminomethyl group on the cyclic peptide residue for achieving improved potency and faster action. ${ }^{113-117}$ Telavancin inhibits Gram-positive bacterial cell wall synthesis by binding to the D-Ala-D-Ala terminus of peptidoglycan in the growing cell wall and interfering with the polymerization and cross-linking of peptidoglycan. The $\mathrm{MIC}_{90}$ of telavancin against $S$. aureus and coagulase-negative staphylococci strains is $\leq 1 \mu \mathrm{g} \mathrm{ml}{ }^{-1}$, regardless of methicillin resistance. ${ }^{118}$ Telavancin was also reported to bind to the cell wall precursor lipid II and disrupts the membrane barrier function. ${ }^{119}$ Telavancin can also inhibit liver enzymes cytochrome P450 3A4 and 3A5, and should not be prescribed for patients with pre-existing moderate to severe renal impairment. ${ }^{120}$ Telavancin has poor oral bioavailability and is administered by intravenous infusion with a halflife of approximately $6.5 \mathrm{~h}^{121}$

Dalbavancin (14, Table 3 and Fig. 2) is a novel secondgeneration lipoglycopeptide antibiotic medication that is more potent than vancomycin and also targets cell wall biosynthesis. ${ }^{122}$ The vancomycin family of natural antimicrobial glycopeptides are highly modified heptapeptides that have five invariant amino acids, while amino acids 1 and 3 are highly

Table 3 Antibiotics and antifungals derived from cyclic peptides approved in the last two decades

\begin{tabular}{|c|c|c|c|c|c|c|c|c|c|c|c|}
\hline No. & $\begin{array}{l}\text { Trade } \\
\text { name }\end{array}$ & Generic name & Target & Indication & Approval & $\mathrm{PDB}$ & $\begin{array}{l}\text { Route of } \\
\text { admin. }\end{array}$ & $\begin{array}{l}\operatorname{Cmax}^{a} \\
(\mathrm{nM})\end{array}$ & $\begin{array}{l}\mathrm{HT} \\
(\mathrm{h})\end{array}$ & Company & $\begin{array}{l}\text { Sales } \\
2020\end{array}$ \\
\hline 12 & Cubicin & Daptomycin & $\begin{array}{l}\text { Membrane pore } \\
\text { formation }\end{array}$ & Antibiotic & 2005 & $1 \mathrm{~T} 5 \mathrm{~N}$ & IV & 113400 & 7.7 & $\begin{array}{l}\text { Merck Sharp \& Dohme } \\
\text { Corp. }\end{array}$ & $\begin{array}{l}\text { \$ } 152 \\
\mathrm{M}\end{array}$ \\
\hline 13 & Vibativ & Telavancin & Cell wall synthesis & Antibiotic & 2009 & & IV fusion & 57400 & 8 & Cumberland Inc. & N. A. \\
\hline 14 & Dalvance & Dalbavancin & Cell wall synthesis & Antibiotic & 2014 & 3RUL & IV fusion & 158000 & 346 & Allergan Ltd. & N. A. \\
\hline 15 & Orbactiv & Oritavancin & Cell wall synthesis & Antibiotic & 2014 & & IV fusion & 77000 & 245 & Melinta Inc. & N. A. \\
\hline 16 & Cancidas & Caspofungin & 1,3-Beta-glucan synthase & Antifungal & 2001 & $2 \mathrm{~N} 2 \mathrm{Q}$ & IV & 8450 & 27 & MERCK \& CO., Inc. & $\begin{array}{l}\$ 430 \\
M\end{array}$ \\
\hline 17 & Mycamine & Micafungin & 1,3-Beta-glucan synthase & Antifungal & 2005 & & IV & 7815 & 13.4 & Astellas Inc. & $\begin{array}{l}\text { \$ } 349 \\
\text { M }\end{array}$ \\
\hline 18 & Eraxis & Anidulafungin & 1,3-Beta-glucan synthase & Antifungal & 2006 & & IV fusion & 9500 & 50.3 & Pfizer & N. A. \\
\hline
\end{tabular}

${ }^{a}$ Pharmacokinetic data was cited from FDA approval summaries. 

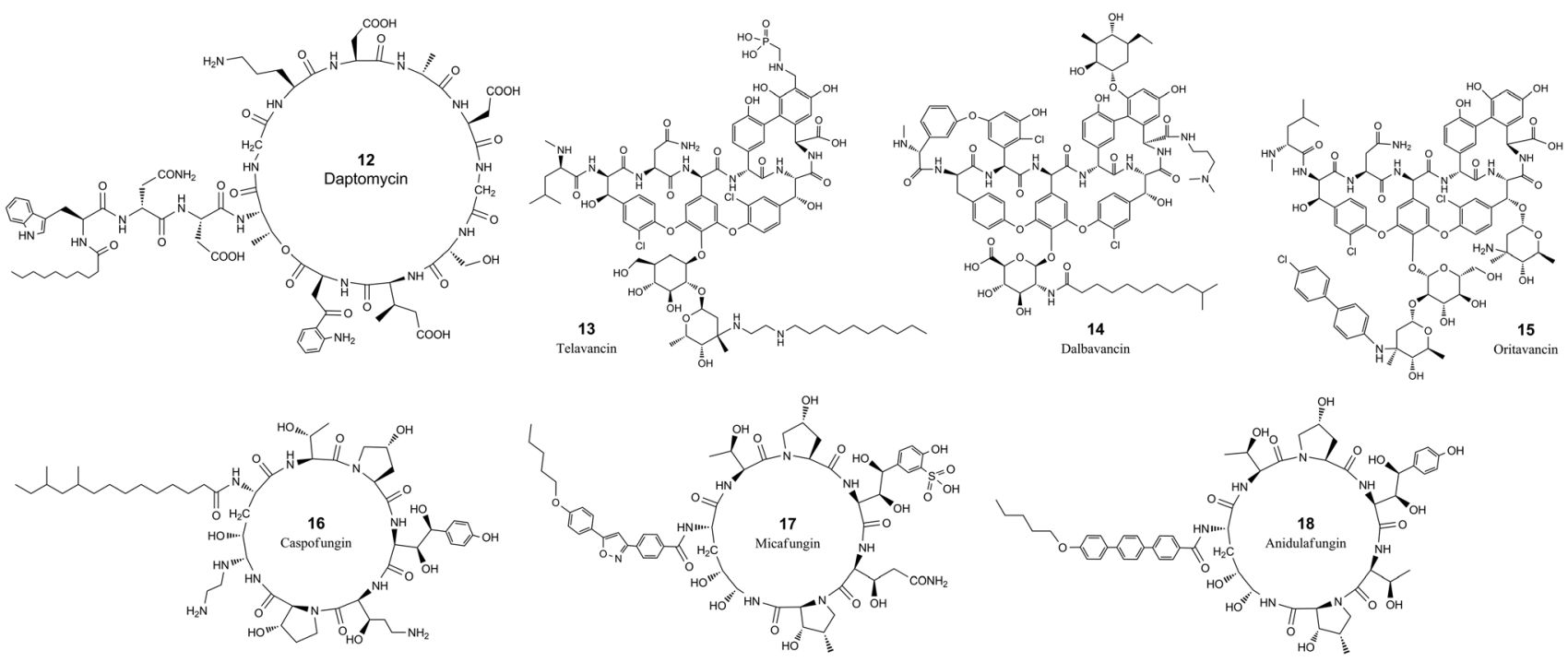

Fig. 2 The chemical structures of cyclic peptide antimicrobial agents from Table 3.

differentiated. ${ }^{123}$ The constancy of the peptide is responsible for binding to the D-alanyl-D-alanine motif, and the sidechain functional groups are derivatized to improve the properties of the peptide. ${ }^{122}$ Dalbavancin possesses a potent and rapid antibactericidal activity in vitro against a broad spectrum of both resistant and susceptible Gram-positive bacteria, including Staphylococcus aureus, MRSA, enterococci, and streptococci. ${ }^{124,125}$ Precursor glycopeptides of dalbavancin is manufactured by fermentation of a selected Nonomuraea strain, followed by carboxyl amidation and saponification for increased potency against staphylococci, particularly CoNS. ${ }^{126}$ The lipophilic side chain of dalbavancin has the common function of anchoring in the bacterial membrane, which is attributed to the increased affinity of dalbavancin for its target. The final dalbavancin is a compound mixture composed of five subtypes, with approximately $90 \%$ as $\mathrm{B} 0,{ }^{127}$ which has a longer half-life of approximately 1 week compared with that of vancomycin which is only 4 to 6 hours. ${ }^{128,129}$ In May 2014, dalbavancin was approved by the FDA for treating Gram-positive skin infections. ${ }^{130}$

Oritavancin (15, Table 3 and Fig. 2) is a synthetic analog of vancomycin derived from chloroeremomycin, and it differs by the addition of a lipophilic $N$-4-(4-chlorophenyl)benzyl side chain. ${ }^{131}$ The heptapeptide core shares the same structure as vancomycin, and the glycosylation is the same as that of chloroeremomycin. This structural alteration imparts improved activity against both vancomycin-susceptible Enterococcus (VSE) and vancomycin-resistant Enterococcus (VRE). ${ }^{132,133}$ The lipophilic side chain in oritavancin anchors the compound to the cell membrane through hydrophobic interactions and at the same time stabilizes the oritavancin dimer. ${ }^{133-135}$ Oritavancin shares a similar mechanism of action to bind the D-Ala-D-Ala stem termini in Gram-positive bacteria for inhibiting transglycosylation during peptidoglycan synthesis. ${ }^{132,136}$ Oritavancin is stable in vivo and is excreted as unchanged. ${ }^{137}$ Oritavancin has a very long half-life of 393 hours, which saves dosing frequency in the treatment of acute bacterial skin and skin structure infections (ABSSSIs). ${ }^{138}$
Caspofungin, micafungin and anidulafungin $(16,17 \& 18$, Table 3 and Fig. 2) all belong to the cyclic hexa-lipopeptide family. They share the same cyclic peptide core structure by targeting the enzyme 1,3- $\beta$-glucan synthase for synthesizing glucan in the cell wall. ${ }^{139,140}$ The cyclization was formed by amidation between the sidechain of the first $\mathrm{N}$-terminal residue of lysine and the C-terminus of the peptide chain. ${ }^{141}$ All three antifungal drugs have clinical efficacy against invasive candidiasis and other forms of systemic mycoses. ${ }^{142}$ Caspofungin is a semisynthetic analog of pneumocandin B0, a natural lipophilic cyclic peptide that was isolated from the fungus Glarea lozoyensis in 1985 and approved for treating yeast and fungal infections under certain conditions in 2001. ${ }^{143,144}$ Caspofungin has a half-life of about 9 days and the majority undergoes ringopening metabolic hydrolysis and $N$-acetylation. ${ }^{145}$ Only around $1.4 \%$ is excreted unchanged in urine. ${ }^{146}$ Micafungin is a semisynthetic analog of the natural cyclic hexapeptide FR901379, by enzymatic deacylation of the N-terminal palmitoyl group and chemical reacylation to the optimal $N$-acyl isoxazole analog. ${ }^{147}$ Micafungin has a poor oral bioavailability and is only intended for parenteral use with a half-life of around 15 hours. ${ }^{148}$ The majority of micafungin is metabolized by enzymatic modification of sidechains and excreted to the feces. ${ }^{149}$ Anidulafungin is also a semisynthetic echinocandin-class cyclic hexapeptide. Anidulafungin is semisynthesized from echinocandin B by diacylation to remove the linoleoyl side chain, followed by three more steps, including reacylation with the terphenylacyl chain. ${ }^{150,151}$ Anidulafungin can inhibit invasive candidiasis via noncompetitive inhibition of beta-(1,3)-glucan-synthase and has good clinical efficacy. ${ }^{152}$ Anidulafungin has a low oral bioavailability of $2-7 \%$ and is administered parenterally. ${ }^{153}$ The half-life of anidulafungin is 27 hours, and the majority is metabolized to a linear peptide by ring-opening hydrolysis. $10 \%$ of the administered anidulafungin remains unchanged and $30 \%$ of the radioactivity of administered anidulafungin is excreted in the feces and $1 \%$ in the urine. ${ }^{154}$ 


\section{A lesson from the withdrawn cyclic peptide drug}

In the past two decades, Omontys (peginesatide) was the only cyclic peptide drug withdrawn. Peginesatide contains two identical cyclic peptides of 21 amino acids attached to a $40 \mathrm{kDa}$ polyethylene glycol (PEG) chain. In the bone marrow, peginesatide binds to the erythropoietin receptor (EpoR) for stimulating the production of red blood cells from erythroid progenitor cells (erythropoiesis). ${ }^{155,156}$ The FDA approved peginesatide for the treatment of anemia in adults on dialysis for chronic kidney disease in March 2012. Peginesatide was withdrawn from the US market in February 2013 due to serious Adverse Drug Reaction (SADR) of a high rate of anaphylactic reactions observed in 28 out of 20000 patients during the first dose IV administration. ${ }^{157}$ It is unclear what causes peginesatide SADR, but it is unlikely that it has a connection with the cyclic peptide motifs itself. ${ }^{158}$

\section{Perspectives and conclusions}

Cyclic peptides have received increasing attention as a unique category of substances with many advantageous characteristics as drugs in comparison to small molecules and macromolecular antibodies. Natural peptides have been the major source of approved cyclic peptides in the last century due to the large number of cyclic peptides present in nature. The generation of specific biological functions by natural evolution also contributed to the drug development of cyclic peptides. Cyclic peptide hormones, such as oxytocin and vasopressin, are potent and selective agonizers and were used in clinics for a long time. Antagonizing cyclic peptides, such as the large number of toxins used by diverse species against competitors and prays, are widely present in nature and are a rich source for drug development.

In the past two decades, the primary trend in peptide drug discovery has been the shift of naturally isolated cyclic peptides toward cyclic peptide analogs optimized for improving potency, stability and pharmacokinetic properties. By incorporating aromatic naphthalene and D-tryptophan into lanreotide, its nanotubes with supramolecular packing were stabilized, which contributed to its extended half-life and ability to suppress hormone levels and activities. From a technical perspective, cyclic peptide drug development benefited from rapid lead discovery with adjustable and expandable optimization by chemical synthesis, which was the milestone in peptide drug development. The mutation of the lipophilic side chain of oritavancin prolonged its half-life and enhanced coverage against several vancomycin-resistant bacteria. Fermentation of cyclic peptides also benefited from modern molecular biology technologies, and the primary sequences of enzymes could be rapidly mutated and optimized for achieving a higher production yield. Increased expression of echinocandin B deacylase in the production host significantly increased the transcription and bioconversion efficiency of anidulafungin. The convenience to incorporate nonnatural elements helped to improve not only the potency, but also the stability and pharmacokinetic/pharmacodynamic properties. Noncanonical amino acids were introduced to improve proteomic resistance. Amino acids with hydrophobic long side chains were incorporated for extending plasma retention time and introducing extra biological activities of cyclic peptides. The population of Fmoc based solid-phase peptide synthesis technologies also greatly reduced the cost of production and promoted cyclic peptide research in individual groups.

The combination of modern recombinant technologies and peptide chemistry has solved the major problems of cyclic peptide production, mutation and optimization of the primary sequences. However, the space of optimizing natural cyclic peptides for achieving cyclic peptide drugs is limited due to the expanded desire to develop cyclic peptide ligands targeting diverse proteins. Recent development of cyclic peptide discovery was characterized by the generation of combinatory libraries that can cover a much larger chemical space and the development of novel screening methodologies for identifying binders and inhibitors. ${ }^{4,159,160}$ Split-and-mix cyclic peptide libraries could be synthesized with millions of diversities and screened against various targets. ${ }^{161-167}$ However, the difficulties associated with sequence identification of cyclic peptides by partial Edman degradation or mass spectrometry limited the applications of one bead-one peptide library. Directed evolutions with genetically displayed cyclic peptide recombinant libraries are increasingly playing more important roles in next-generation cyclic peptide drug discovery. Display systems such as mRNA display, ${ }^{168-171}$ DNA display ${ }^{172}$ and phage display ${ }^{22,173,174}$ offer the advantages of large library diversity and rapid screening, and have resulted in the discovery of a good portion of cyclic peptides in clinic development. Compared with the typical diversity of only a few thousands for conventional natural and synthetic cyclic peptide libraries, the diversity of cyclic peptide libraries built by genetic recombinant technologies is several orders higher. The introduction of various cyclization strategies, noncanonical amino acids and even functional moieties have further increased the functionality of recombinant libraries, such as chemical stability, metabolic stability and uniform conformation. The development of selection strategies also enabled the discovery of cyclic peptides that have special properties such as cell membrane permeation ability and oral bioavailability.

A second trend in cyclic peptide drug discovery is the development of cyclic peptide conjugates to achieve a selective delivery of different effector molecules to target tissue. Besides the drug itself, which induces the desired biological functions, and the linker, which controls drug release, cyclic peptides have been investigated intensively to facilitate sufficient target selectivity for engineering cyclic peptide drug conjugates (PDCs). Cyclic peptides, possessing the characteristics of both antibodies and small molecules, have the capacity to penetrate tissue freely and deeply, and selectively and effectively interact with receptors that are specific for certain cell types. Furthermore, PDCs are more advanced for low immunogenicity, large-scale synthesis using solid-phase synthesis, low production 
cost, and relatively good pharmacokinetics. When conjugated with chemotherapeutic or cytotoxic agents, PDCs have effects on tumor growth inhibition and elimination. Cyclic peptides are also conjugated with positron-emitting radioisotopes and gamma-emitting radioisotopes for developing positron emission tomography (PET) and single-photon emission computed tomography (SPECT) imaging agents.

In the coming decades, the position of cyclic peptides in the pharmaceutical industry is expected to outperform small molecules and antibodies in certain applications due to their structural complexity, large surface binding area and relatively small size. Orally available cell penetrating peptides will be one of the most important focuses of cyclic peptide studies, and the reduced production cost of cyclic peptides will contribute to the growth of cyclic peptide development.

\section{Conflicts of interest}

There are no conflicts to declare.

\section{Acknowledgements}

This work was supported by Shanghai Pujiang Program, Science and Technology Commission of Shanghai Municipality (\#20PJ1415900 to S. C.).

\section{References}

1 M. Bliss, Rewriting Medical History: Charles Best and the Banting and Best myth, J. Hist. Med. Allied Sci., 1993, 48(3), 253-274.

2 S. S. Usmani, et al., THPdb: Database of FDA-approved peptide and protein therapeutics, PLoS One, 2017, 12(7), e0181748.

3 A. Zorzi, K. Deyle and C. Heinis, Cyclic peptide therapeutics: past, present and future, Curr. Opin. Chem. Biol., 2017, 38, 24-29.

4 C. Sohrabi, A. Foster and A. Tavassoli, Methods for generating and screening libraries of genetically encoded cyclic peptides in drug discovery, Nat. Rev. Chem., 2020, 4(2), 90-101.

5 D. J. Craik, Chemistry. Seamless proteins tie up their loose ends, Science, 2006, 311(5767), 1563-1564.

6 A. Angelini, et al., Bicyclic peptide inhibitor reveals large contact interface with a protease target, ACS Chem. Biol., 2012, 7(5), 817-821.

7 M. Empting, An Introduction to Cyclic Peptides, in Cyclic Peptides: From Bioorganic Synthesis to Applications, ed. J. Koehnke, J. Naismith and W. A. van der Donk, 2018, The Royal Society of Chemistry.

8 S. D. Appavoo, et al., Conformational Control of Macrocycles by Remote Structural Modification, Chem. Rev., 2019, 119(17), 9724-9752.

9 A. T. Bockus, C. M. McEwen and R. S. Lokey, Form and function in cyclic peptide natural products: a pharmacokinetic perspective, Curr. ToMed. Chem., 2013, 13(7), 821-836.

10 P. G. Dougherty, A. Sahni and D. Pei, Understanding Cell Penetration of Cyclic Peptides, Chem. Rev., 2019, 119(17), 10241-10287.

11 A. A. Vinogradov, Y. Yin and H. Suga, Macrocyclic Peptides as Drug Candidates: Recent Progress and Remaining Challenges, J. Am. Chem. Soc., 2019, 141(10), 4167-4181.

12 R. E. Kontermann, Half-life extended biotherapeutics, Expert Opin. Biol. Ther., 2016, 16(7), 903-915.

13 S. C. Penchala, et al., A biomimetic approach for enhancing the in vivo half-life of peptides, Nat. Chem. Biol., 2015, 11(10), 793-798.

14 K. Chen, J. Xie and X. Chen, RGD-human serum albumin conjugates as efficient tumor targeting probes, Mol. Imaging, 2009, 8(2), 65-73.

$15 \mathrm{M}$. Yu, et al., Battle of GLP-1 delivery technologies, Adv. Drug Delivery Rev., 2018, 130, 113-130.

16 D. Gang, D. W. Kim and H. S. Park, Cyclic Peptides: Promising Scaffolds for Biopharmaceuticals, Genes, 2018, 9, 11.

17 M. A. Abdalla and L. J. McGaw, Natural Cyclic Peptides as an Attractive Modality for Therapeutics: A Mini Review, Molecules, 2018, 23, 8.

18 E. Muratspahić, et al., Harnessing cyclotides to design and develop novel peptide GPCR ligands, RSC Chem. Biol., 2020, 1(4), 177-191.

19 C. J. White and A. K. Yudin, Contemporary strategies for peptide macrocyclization, Nat. Chem., 2011, 3(7), 509-524.

20 H. Y. Chow, et al., Ligation Technologies for the Synthesis of Cyclic Peptides, Chem. Rev., 2019, 119(17), 9971-10001.

21 J. N. Lambert, J. P. Mitchell and K. D. Roberts, The synthesis of cyclic peptides, J. Chem. Soc., Perkin Trans. 1, 2001, (5), 471-484.

22 C. Heinis, et al., Phage-encoded combinatorial chemical libraries based on bicyclic peptides, Nat. Chem. Biol., 2009, 5(7), 502-507.

23 S. Chen, et al., Peptide ligands stabilized by small molecules, Angew. Chem., Int. Ed., 2014, 53(6), 1602-1606.

24 N. J. Yang and M. J. Hinner, Getting across the cell membrane: an overview for small molecules, peptides, and proteins, Methods Mol. Biol., 2015, 1266, 29-53.

25 C. Bechara and S. Sagan, Cell-penetrating peptides: 20 years later, where do we stand?, FEBS Lett., 2013, 587(12), 1693-1702.

26 M. Kristensen, D. Birch and H. Morck, Nielsen, Applications and Challenges for Use of Cell-Penetrating Peptides as Delivery Vectors for Peptide and Protein Cargos., Int. J. Mol. Sci., 2016, 17(2), 185.

27 I. Ruseska and A. Zimmer, Internalization mechanisms of cell-penetrating peptides, Beilstein J. Nanotechnol., 2020, 11, 101-123.

28 S. G. Patel, et al., Cell-penetrating peptide sequence and modification dependent uptake and subcellular distribution of green florescent protein in different cell lines, Sci. Rep., 2019, 9(1), 6298. 
29 A. C. Rand, et al., Optimizing PK properties of cyclic peptides: the effect of side chain substitutions on permeability and clearance(), MedChemComm, 2012, 3(10), 1282-1289.

30 T. Rezai, et al., Conformational flexibility, internal hydrogen bonding, and passive membrane permeability: successful in silico prediction of the relative permeabilities of cyclic peptides, J. Am. Chem. Soc., 2006, 128(43), 14073-14080.

31 E. Biron, et al., Improving oral bioavailability of peptides by multiple N-methylation: somatostatin analogues, Angew. Chem., Int. Ed., 2008, 47(14), 2595-2599.

32 Z. Qian, et al., Early endosomal escape of a cyclic cellpenetrating peptide allows effective cytosolic cargo delivery, Biochemistry, 2014, 53(24), 4034-4046.

33 Approval Date(s) and History, Letters, Labels, Reviews for ISTODAX. Available from: https://www.accessdata.fda.gov/ scripts/cder/daf/index.cfm?event=overview.process\&ApplNo= 022393.

34 Approval Date(s) and History, Letters, Labels, Reviews for LUPKYNIS. Available from: https:/www.accessdata.fda. gov/scripts/cder/daf/index.cfm?event=overview.process\&ApplNo= 213716.

35 Drug Approval Package for Istodax. Available from: https:/www.accessdata.fda.gov/drugsatfda_docs/nda/2009/ 022393s000TOC.cfm.

36 H. Ueda, et al., FR901228, a novel antitumor bicyclic depsipeptide produced by Chromobacterium violaceum No. 968. I. Taxonomy, fermentation, isolation, physicochemical and biological properties, and antitumor activity, J. Antibiot., 1994, 47(3), 301-310.

37 K. W. Li, et al., Total synthesis of the antitumor depsipeptide FR-901,228, J. Am. Chem. Soc., 1996, 118(30), 7237-7238.

38 B. C. Valdez, et al., Romidepsin targets multiple survival signaling pathways in malignant T cells, Blood Cancer J., 2015, 5, e357.

39 H. Nakajima, et al., FR901228, a potent antitumor antibiotic, is a novel histone deacetylase inhibitor, Exp. Cell Res., 1998, 241(1), 126-133.

40 S. Woo, et al., Population pharmacokinetics of romidepsin in patients with cutaneous T-cell lymphoma and relapsed peripheral T-cell lymphoma, Clin. Cancer Res., 2009, 15(4), 1496-1503.

41 Product monograph of istodax. Available from: https:// www.bms.com/assets/bms/ca/documents/productmonograph/ ISTODAX_EN_PM.pdf.

42 S. J. Harrison, et al., A focus on the preclinical development and clinical status of the histone deacetylase inhibitor, romidepsin (depsipeptide, Istodax((R))), Epigenomics, 2012, 4(5), 571-589.

43 Bristol Myers Squibb Statement on $\operatorname{Istodax}^{\circledR}$ (romidepsin) Relapsed/Refractory Peripheral T-cell Lymphoma U.S. Indicatio. Available from: https://news.bms.com/news/corporatefinancial/2021/Bristol-Myers-Squibb-Statement-on-Istodaxromidepsin-Relapsed-Refractory-Peripheral-T-cell-LymphomaU.S.-Indication/default.aspx.
44 Drug Approval Package for lupkynis. Available from: https://www.accessdata.fda.gov/drugsatfda_docs/nda/2021/ 213716Orig1s000TOC.cfm.

45 Voclosporin, in Meyler's Side Effects of Drugs, ed. J. K. Aronson, 2016, Sixteenth Edition, Elsevier, Oxford. pp. 500-501.

46 E. Anglade, L. J. Aspeslet and S. L. Weiss, A new agent for the treatment of noninfectious uveitis: rationale and design of three LUMINATE (Lux Uveitis Multicenter Investigation of a New Approach to Treatment) trials of steroidsparing voclosporin, Clin. Ophthalmol., 2008, 2(4), 693-702.

47 A. Kuglstatter, et al., Structural basis for the cyclophilin A binding affinity and immunosuppressive potency of EISA247 (voclosporin), Acta Crystallogr., Sect. D: Biol. Crystallogr., 2011, 67(Pt 2), 119-123.

48 A. Lawen, Biosynthesis of cyclosporins and other natural peptidyl prolyl cis/trans isomerase inhibitors, Biochim. Biophys. Acta, 2015, 1850(10), 2111-2120.

49 C. Schultz, Voclosporin as a treatment for noninfectious uveitis, Ophthalmol. Eye Dis., 2013, 5, 5-10.

50 A. S. Hauser, et al., Trends in GPCR drug discovery: new agents, targets and indications, Nat. Rev. Drug Discovery, 2017, 16(12), 829-842.

51 W. K. Chan, et al., GLASS: a comprehensive database for experimentally validated GPCR-ligand associations, Bioinformatics, 2015, 31(18), 3035-3042.

52 C. W. Gruber, M. Muttenthaler and M. Freissmuth, Ligandbased peptide design and combinatorial peptide libraries to target G protein-coupled receptors, Curr. Pharm. Des., 2010, 16(28), 3071-3088.

53 E. Muratspahic, M. Freissmuth and C. W. Gruber, NatureDerived Peptides: A Growing Niche for GPCR Ligand Discovery, Trends Pharmacol. Sci., 2019, 40(5), 309-326.

54 A. Zorzi, et al., Acylated heptapeptide binds albumin with high affinity and application as tag furnishes long-acting peptides, Nat. Commun., 2017, 8, 16092.

55 D. Chung, et al., Determination of disulfide bridge pattern in omega-conopeptides, Int. J. Pept. Protein Res., 1995, 46(34), 320-325.

56 V. J. Basus, et al., Solution structure of omega-conotoxin MVIIA using 2D NMR spectroscopy, FEBS Lett., 1995, 370(3), 163-169.

57 T. Kohno, et al., Three-dimensional structure in solution of the calcium channel blocker omega-conotoxin MVIIA, Biochemistry, 1995, 34(32), 10256-10265.

58 Approval Date(s) and History, Letters, Labels, Reviews for PRIALT. Available from: https://www.accessdata. fda.gov/scripts/cder/daf/index.cfm?event=overview.process\& ApplNo $=021060$.

59 J. G. McGivern, Ziconotide: a review of its pharmacology and use in the treatment of pain, Neuropsychiatr. Dis. Treat., 2007, 3(1), 69-85.

60 Drug Approval Package for Prialt. Available from: https:// www.accessdata.fda.gov/drugsatfda_docs/nda/2004/21-060_ Prialt.cfm. 
61 M. Vazquez Roque and M. Camilleri, Linaclotide, a synthetic guanylate cyclase $\mathrm{C}$ agonist, for the treatment of functional gastrointestinal disorders associated with constipation, Exp. Rev. Gastroenterol. Hepatol., 2011, 5(3), 301-310.

62 A. P. Bryant, et al., Linaclotide is a potent and selective guanylate cyclase $\mathrm{C}$ agonist that elicits pharmacological effects locally in the gastrointestinal tract, Life Sci., 2010, 86(19-20), 760-765.

63 K. Shailubhai, et al., Plecanatide, an oral guanylate cyclase $\mathrm{C}$ agonist acting locally in the gastrointestinal tract, is safe and well-tolerated in single doses, Dig. Dis. Sci., 2013, 58(9), 2580-2586.

64 K. Shailubhai, et al., Plecanatide and dolcanatide, novel guanylate cyclase-C agonists, ameliorate gastrointestinal inflammation in experimental models of murine colitis, World J. Gastrointest. Pharmacol. Ther., 2015, 6(4), 213-222.

65 Y. Yang, et al., Linaclotide in irritable bowel syndrome with constipation: A Phase 3 randomized trial in China and other regions, J. Gastroenterol. Hepatol., 2018, 33(5), 980-989.

66 R. H. Thomas and K. Allmond, Linaclotide (Linzess) for Irritable Bowel syndrome With Constipation and For Chronic Idiopathic Constipation, Proc. Trans., 2013, 38(3), 154-160.

67 A. Brancale, et al., Therapeutically targeting guanylate cyclase-C: computational modeling of plecanatide, a uroguanylin analog, Pharmacol. Res. Perspect., 2017, 5(2), e00295.

68 M. K. Ahsan, et al., Linaclotide activates guanylate cyclase$\mathrm{C} / \mathrm{cGMP} /$ protein kinase-II-dependent trafficking of CFTR in the intestine, Physiol. Rep., 2017, 5(11), e13299.

69 R. W. Busby and S. Ortiz, Clarification of linaclotide pharmacology presented in a recent clinical study of plecanatide, Dig. Dis. Sci., 2014, 59(5), 1066-1067.

70 A. Jarmuz, et al., Emerging treatments in Neurogastroenterology: Perspectives of guanylyl cyclase $\mathrm{C}$ agonists use in functional gastrointestinal disorders and inflammatory bowel diseases, Neurogastroenterol. Motil., 2015, 27(8), 1057-1068.

71 Z. T. Al-Salama and Y. Y. Syed, Plecanatide: First Global Approval, Drugs, 2017, 77(5), 593-598.

72 T. J. O'Toole and S. Sharma, Physiology, Somatostatin, StatPearls, 2021, Treasure Island (FL).

73 R. M. Paragliola and R. Salvatori, Novel Somatostatin Receptor Ligands Therapies for Acromegaly, Front. Endocrinol., 2018, 9, 78.

74 European Medicines Agency recommends approval of new medicine for Cushing's disease. Available from: https:// www.ema.europa.eu/en/documents/press-release/europeanmedicines-agency-recommends-approval-new-medicinecushings-disease_en.pdf.

75 Drug Approval Package for Signifor. Available from: https://www.accessdata.fda.gov/drugsatfda_docs/nda/2012/ 200677Orig1s000TOC.cfm.

76 Drug Approval Package for Signifor LAR. Available from: https://www.accessdata.fda.gov/drugsatfda_docs/nda/2014/ 203255Orig1s000TOC.cfm.
77 J. M. Kuhn, et al., Pharmacokinetic study and effects on growth hormone secretion in healthy volunteers of the new somatostatin analogue BIM 23014, Eur. J. Clin. Pharmacol., 1993, 45(1), 73-77.

78 I. Morange, et al., Slow release lanreotide treatment in acromegalic patients previously normalized by octreotide, J. Clin. Endocrinol. Metab., 1994, 79(1), 145-151.

79 J. M. Kuhn, et al., Pharmacokinetic and pharmacodynamic properties of a long-acting formulation of the new somatostatin analogue, lanreotide, in normal healthy volunteers, Br. J. Clin. Pharmacol., 1994, 38(3), 213-219.

80 Drug Approval Package for lanreotide. Available from: https://www.accessdata.fda.gov/drugsatfda_docs/nda/2007/ 022074s000TOC.cfm.

81 Editorials, Separation of the active principles of the posterior lobe of the pituitary gland, J. Am. Med. Assoc., 1928, 90(8), 618-619.

82 R. A. Turner, J. G. Pierce and V. V. Du, The purification and the amino acid content of vasopressin preparations., J. Biol. Chem., 1951, 191(1), 21-28.

83 R. Acher and J. Chauvet, La structure de la vasopressine de boeuf, Biochem. Biophys. Acta, 1954, 14, 421-429.

84 V.d. Vigneaud, H. C. Lawler and E. A. Popenoe, Enzymatic cleavage of glycinamide from vasopressin and a proposed structure for this pressor-antidiuretic hormone of the posterior pituitary, J. Am. Chem. Soc., 1953, 75(19), 4880-4881.

85 J. Demiselle, et al., Vasopressin and its analogues in shock states: a review, Ann. Intensive Care, 2020, 10(1), 9.

86 Drug Approval Package for Vasostrict. Available from: https:/www.accessdata.fda.gov/drugsatfda_docs/nda/ 2014.204485Orig1s000TOC.cfm.

87 A. Delmas, et al., Clinical review: vasopressin and terlipressin in septic shock patients, Crit. Care, 2005, 9(2), 212-222.

88 J. W. Czaczkes, C. R. Kleeman and M. Koenig, Physiologic Studies of Antidiuretic Hormone by Its Direct Measurement in Human Plasma, J. Clin. Invest., 1964, 43, 1625-1640.

89 J. Bosch, D. Lebrec and S. A. Jenkins, Development of analogues: successes and failures, Scand. J. Gastroenterol., Suppl., 1998, 226, 3-13.

90 K. Wisniewski, et al., New, potent, selective, and shortacting peptidic V1a receptor agonists, J. Med. Chem., 2011, 54(13), 4388-4398.

91 Z. R. Belkin, J. M. Krapf and A. T. Goldstein, Drugs in early clinical development for the treatment of female sexual dysfunction, Expert Opin. Invest. Drugs, 2015, 24(2), 159-167.

92 S. H. King, et al., Melanocortin receptors, melanotropic peptides and penile erection, Curr. Top. Med. Chem., 2007, 7(11), 1098-1106.

93 S. Sharma, et al., Current Mechanistic and Pharmacodynamic Understanding of Melanocortin-4 Receptor Activation, Molecules, 2019, 24, 10.

94 J. Pfaus, F. Giuliano and H. Gelez, Bremelanotide: an overview of preclinical CNS effects on female sexual function, J. Sex Med., 2007, 4(suppl 4), 269-279. 
95 Highlights Of Prescribing Information For Vyleesi. Available from: https:/www.accessdata.fda.gov/drugsatfda_ docs/label/2019/210557s000lbl.pdf.

96 K. Y. Chen, et al., RM-493, a melanocortin-4 receptor (MC4R) agonist, increases resting energy expenditure in obese individuals, J. Clin. Endocrinol. Metab., 2015, 100(4), 1639-1645.

97 R. D. Cone, Studies on the physiological functions of the melanocortin system, Endocr. Rev., 2006, 27(7), 736-749.

98 A. S. Garfield, et al., A neural basis for melanocortin-4 receptor-regulated appetite, Nat. Neurosci., 2015, 18(6), 863-871.

99 G. W. Kim, et al., Regulation of appetite to treat obesity, Expert Rev. Clin. Pharmacol., 2011, 4(2), 243-259.

100 E. Pilitsi, et al., Pharmacotherapy of obesity: available medications and drugs under investigation, Metabolism, 2019, 92, 170-192.

101 T. H. Collet, et al., Evaluation of a melanocortin-4 receptor (MC4R) agonist (Setmelanotide) in MC4R deficiency, Mol. Metab., 2017, 6(10), 1321-1329.

102 P. Kuhnen, et al., Proopiomelanocortin Deficiency Treated with a Melanocortin-4 Receptor Agonist, N. Engl. J. Med., 2016, 375(3), 240-246.

103 K. Clement, et al., MC4R agonism promotes durable weight loss in patients with leptin receptor deficiency, Nat. Med., 2018, 24(5), 551-555.

104 Microbiology, Chapter 14 | Antimicrobial Drugs. Available from: https://openstax.org/books/microbiology/pages/14introduction.

105 M. M. Mullis, et al., Diversity, Ecology, and Prevalence of Antimicrobials in Nature, Front. Microbiol., 2019, 10, 2518.

106 J. R. Knox and R. F. Pratt, Different modes of vancomycin and D-alanyl-D-alanine peptidase binding to cell wall peptide and a possible role for the vancomycin resistance protein, Antimicrob. Agents Chemother., 1990, 34(7), 1342-1347.

107 A. Falanga, et al., Cyclic Peptides as Novel Therapeutic Microbicides: Engineering of Human Defensin Mimetics, Molecules, 2017, 22, 7.

108 V. Miao, et al., Daptomycin biosynthesis in Streptomyces roseosporus: cloning and analysis of the gene cluster and revision of peptide stereochemistry, Microbiology, 2005, 151(Pt 5), 1507-1523.

109 J. N. Steenbergen, et al., Daptomycin: a lipopeptide antibiotic for the treatment of serious Gram-positive infections, J. Antimicrob. Chemother., 2005, 55(3), 283-288.

110 J. Pogliano, N. Pogliano and J. A. Silverman, Daptomycinmediated reorganization of membrane architecture causes mislocalization of essential cell division proteins, J. Bacteriol., 2012, 194(17), 4494-4504.

111 A. C. Papanicolaou, et al., Evidence for right-hemisphere involvement in recovery from aphasia, Arch. Neurol., 1988, 45(9), 1025-1029.

112 B. H. Dvorchik, et al., Daptomycin pharmacokinetics and safety following administration of escalating doses once daily to healthy subjects, Antimicrob. Agents Chemother., 2003, 47(4), 1318-1323.
113 K. Sterling, et al., Specific mitochondrial binding sites for triiodothyronine, Trans. Assoc. Am. Physicians, 1979, 92, 334-345.

114 S. S. Hegde, et al., Pharmacodynamics of telavancin (TD6424), a novel bactericidal agent, against Gram-positive bacteria, Antimicrob. Agents Chemother., 2004, 48(8), 3043-3050.

115 Food and Drug Administration, FDA labelling information, FDA website, 2009. Available from: http://www.accessdata. fda.gov/drugsatfda_docs/label/2009/022110s000lbl.pdf.

116 S. Laohavaleeson, J. L. Kuti and D. P. Nicolau, Telavancin: a novel lipoglycopeptide for serious Gram-positive infections, Expert Opin. Invest. Drugs, 2007, 16(3), 347-357.

117 P. Plotkin, et al., Telavancin (vibativ), a new option for the treatment of Gram-positive infections, Proc. Trans., 2011, 36(3), 127-138.

118 R. E. Mendes, et al., Update on the telavancin activity tested against European staphylococcal clinical isolates (2009-2010), Diagn. Microbiol. Infect. Dis., 2011, 71(1), 93-97.

119 C. S. Lunde, et al., Telavancin disrupts the functional integrity of the bacterial membrane through targeted interaction with the cell wall precursor lipid II, Antimicrob. Agents Chemother., 2009, 53(8), 3375-3383.

120 L. J. Scott, Telavancin: a review of its use in patients with nosocomial pneumonia, Drugs, 2013, 73(16), 1829-1839.

121 V. Al Jalali and M. Zeitlinger, Clinical Pharmacokinetics and Pharmacodynamics of Telavancin Compared with the Other Glycopeptides, Clin. Pharmacokinet., 2018, 57(7), 797-816.

122 A. Y. Chen, M. J. Zervos and J. A. Vazquez, Dalbavancin: a novel antimicrobial, Int. J. Clin. Pract., 2007, 61(5), 853-863.

123 A. Malabarba and R. Ciabatti, Glycopeptide derivatives, Curr. Med. Chem., 2001, 8(14), 1759-1773.

124 B. S. Zuckerman, H. Amaro and W. Beardslee, Mental health of adolescent mothers: the implications of depression and drug use, J. Dev. Behav. Pediatr., 1987, 8(2), 111-116.

125 R. E. Mendes, et al., Activity of oritavancin tested against uncommonly isolated Gram-positive pathogens responsible for documented infections in hospitals worldwide, J. Antimicrob. Chemother., 2014, 69(6), 1579-1581.

126 A. Malabarba and B. P. Goldstein, Origin, structure, and activity in vitro and in vivo of dalbavancin, J. Antimicrob. Chemother., 2005, 55(suppl_2), ii15-ii20.

127 M. Stogniew, Dalbavancin compositions for treatment of bacterial infections, US, 2004.

128 A. Leighton, et al., Tolerability, pharmacokinetics, and serum bactericidal activity of intravenous dalbavancin in healthy volunteers, Antimicrob. Agents Chemother., 2004, 48(3), 940-945.

129 E. Seltzer, et al., Once-weekly dalbavancin versus standardof-care antimicrobial regimens for treatment of skin and soft-tissue infections, Clin. Infect. Dis., 2003, 37(10), 1298-1303. 
130 Drug Approval Package for Dalvance. Available from: https:/www.accessdata.fda.gov/drugsatfda_docs/nda/2014/ 021883Orig1s000TOC.cfm.

131 G. G. Zhanel, F. Schweizer and J. A. Karlowsky, Oritavancin: mechanism of action, Clin. Infect. Dis., 2012, 54(suppl 3), S214-S219.

132 G. J. Patti, et al., Vancomycin and oritavancin have different modes of action in Enterococcus faecium, J. Mol. Biol., 2009, 392(5), 1178-1191.

133 A. Belley, et al., Ultrastructural effects of oritavancin on methicillin-resistant Staphylococcus aureus and vancomycin-resistant Enterococcus, Antimicrob. Agents Chemother., 2009, 53(2), 800-804.

134 N. E. Allen and T. I. Nicas, Mechanism of action of oritavancin and related glycopeptide antibiotics, FEMS Microbiol. Rev., 2003, 26(5), 511-532.

135 A. Belley, et al., Oritavancin kills stationary-phase and biofilm Staphylococcus aureus cells in vitro, Antimicrob. Agents Chemother., 2009, 53(3), 918-925.

136 S. J. Kim, et al., Oritavancin exhibits dual mode of action to inhibit cell-wall biosynthesis in Staphylococcus aureus, J. Mol. Biol., 2008, 377(1), 281-293.

137 D. J. Cada and D. E. Baker, Oritavancin diphosphate, Hosp. Pharm., 2014, 49(11), 1049-1060.

138 L. D. Saravolatz and G. E. Stein, Oritavancin: A Long-HalfLife Lipoglycopeptide, Clin. Infect. Dis., 2015, 61(4), 627-632.

139 M. B. Kurtz, et al., Morphological effects of lipopeptides against Aspergillus fumigatus correlate with activities against (1,3)-beta-D-glucan synthase, Antimicrob. Agents Chemother., 1994, 38(7), 1480-1489.

140 N. Robbins, G. D. Wright and L. E. Cowen, Antifungal Drugs: The Current Armamentarium and Development of New Agents, Microbiol. Spectr., 2016, 4, 5.

141 W. Huttel, Echinocandins: structural diversity, biosynthesis, and development of antimycotics, Appl. Microbiol. Biotechnol., 2021, 105(1), 55-66.

142 D. W. Denning, Echinocandins: a new class of antifungal, J. Antimicrob. Chemother., 2002, 49(6), 889-891.

143 Drug Approval Package for Cancidas. Available from: https:/www.accessdata.fda.gov/drugsatfda_docs/nda/2001/ 21227_Cancidas.cfm.

144 J. M. Balkovec, et al., Discovery and development of first in class antifungal caspofungin (CANCIDAS(R))-a case study, Nat. Prod. Rep., 2014, 31(1), 15-34.

145 G. Kofla and M. Ruhnke, Pharmacology and metabolism of anidulafungin, caspofungin and micafungin in the treatment of invasive candidosis: review of the literature, Eur. J. Med. Res., 2011, 16(4), 159-166.

146 D. W. Denning, Echinocandin antifungal drugs, Lancet, 2003, 362(9390), 1142-1151.

147 S. Hashimoto, Micafungin: a sulfated echinocandin, J. Antibiot., 2009, 62(1), 27-35.

148 R. E. Wasmann, et al., Clinical Pharmacokinetics and Pharmacodynamics of Micafungin, Clin. Pharmacokinet., 2018, 57(3), 267-286.
149 J. Houst, J. Spizek and V. Havlicek, Antifungal Drugs, Metabolites, 2020, 10, 3.

150 D. W. Denning, Echinocandins and pneumocandins-a new antifungal class with a novel mode of action, J. Antimicrob. Chemother., 1997, 40(5), 611-614.

151 L. Shao, et al., Efficient bioconversion of echinocandin B to its nucleus by overexpression of deacylase genes in different host strains, Appl. Environ. Microbiol., 2013, 79(4), 1126-1133.

152 S. L. Davis and J. A. Vazquez, Anidulafungin: an evidencebased review of its use in invasive fungal infections, Core Evid., 2008, 2(4), 241-249.

153 Summary Of Product Characteristics For Ecalta. Available from: https://www.ema.europa.eu/en/documents/productinformation/ecalta-epar-product-information_en.pdf.

154 T. J. Walsh, et al., Treatment of aspergillosis: clinical practice guidelines of the Infectious Diseases Society of America, Clin. Infect. Dis., 2008, 46(3), 327-360.

155 J. M. Green, et al., Peginesatide and erythropoietin stimulate similar erythropoietin receptor-mediated signal transduction and gene induction events, Exp. Hematol., 2012, 40(7), 575-587.

156 R. Verma, et al., The Erythropoiesis Stimulating Agent Omontys/Peginesatide up-Modulates Erythroid Progenitor Formation, and Cell Surface Erythropoietin Receptor Levels, Blood, 2012, 120(21), 2089.

157 C. L. Bennett, et al., Anaphylaxis and hypotension after administration of peginesatide, N. Engl. J. Med., 2014, 370(21), 2055-2056.

158 T. Hermanson, C. L. Bennett and I. C. Macdougall, Peginesatide for the treatment of anemia due to chronic kidney disease - an unfulfilled promise, Expert Opin. Drug Saf., 2016, 15(10), 1421-1426.

159 K. Shinbara, et al., Methodologies for Backbone Macrocyclic Peptide Synthesis Compatible With Screening Technologies, Front. Chem., 2020, 8, 447.

$160 \mathrm{~J}$. Valentine and A. Tavassoli, Genetically Encoded Cyclic Peptide Libraries: From Hit to Lead and Beyond, Methods Enzymol., 2018, 610, 117-134.

161 T. Liu, et al., Synthesis and screening of a cyclic peptide library: discovery of small-molecule ligands against human prolactin receptor, Bioorg. Med. Chem., 2009, 17(3), 1026-1033.

162 W. M. Hewitt, et al., Cell-permeable cyclic peptides from synthetic libraries inspired by natural products, J. Am. Chem. Soc., 2015, 137(2), 715-721.

163 W. Tegge, W. Bautsch and R. Frank, Synthesis of cyclic peptides and peptide libraries on a new disulfide linker, J. Pept. Sci., 2007, 13(10), 693-699.

164 V. Adebomi, et al., CyClick Chemistry for the Synthesis of Cyclic Peptides, Angew. Chem., Int. Ed., 2019, 58(52), 19073-19080.

165 R. Wills, V. Adebomi and M. Raj, Site-Selective Peptide Macrocyclization, ChemBioChem, 2021, 22(1), 52-62.

166 B. Li, et al., Construction of Natural-Product-Like Cyclophane-Braced Peptide Macrocycles via sp(3) C-H Arylation, J. Am. Chem. Soc., 2019, 141(23), 9401-9407. 
$167 \mathrm{X} . \mathrm{Hu}$, et al., Construction of Peptide Macrocycles via Radical-Mediated Intramolecular C-H Alkylations, Org. Lett., 2021, 23(3), 716-721.

168 Z. Ma and M. C. T. Hartman, In Vitro Selection of Unnatural Cyclic Peptide Libraries via mRNA Display, in Ribosome Display and Related Technologies: Methods and Protocols, ed. J. A. Douthwaite and R. H. Jackson, 2012, Springer New York, New York, NY, pp. 367-390.

169 T. Passioura and H. Suga, A RaPID way to discover nonstandard macrocyclic peptide modulators of drug targets, Chem. Commun., 2017, 53(12), 1931-1940.

170 T. Passioura, et al., Display Selection of Exotic Macrocyclic Peptides Expressed under a Radically Reprogrammed 23 Amino Acid Genetic Code, J. Am. Chem. Soc., 2018, 140(37), 11551-11555.
171 R. Takatsuji, et al., Ribosomal Synthesis of BackboneCyclic Peptides Compatible with In Vitro Display, J. Am. Chem. Soc., 2019, 141(6), 2279-2287.

172 D. Neri and R. A. Lerner, DNA-Encoded Chemical Libraries: A Selection System Based on Endowing Organic Compounds with Amplifiable Information, Annu. Rev. Biochem., 2018, 87, 479-502.

173 S. Chen, et al., Identification of highly selective covalent inhibitors by phage display, Nat. Biotechnol., 2021, 39(4), 490-498.

174 A. Glas, et al., Constrained peptides with target-adapted cross-links as inhibitors of a pathogenic protein-protein interaction, Angew. Chem., Int. Ed., 2014, 53(9), 2489-2493. 